\title{
DECOLONIALIDADE E EDUCAÇÃO DO CAMPO: DIÁLOGOS EM CONSŢRUÇÃO
}

\author{
Jaqueline Cardoso Zeferino* \\ Joana Célia dos Passos** \\ Elison Antonio Paim****
}

Resumo: Que desafios estão postos à formação de educadoras e educadores do campo para que gênero, raça e natureza sejam incorporados plenamente ao seu marco conceitual, metodológico e político, enquanto categorias úteis para a superação da lógica monorracial, monocultural e heteropatriarcal que organiza a educação brasileira? Esta é a questão que propomos para conduzir as reflexões sobre os diálogos em construção entre decolonialidade e formação de educadoras e educadores do campo. Neste ensaio, cujo o ponto de partida é a atuação junto aos movimentos sociais do campo, especialmente os movimentos de mulheres, negros, quilombolas e feministas, decolonialidade e educação do campo são compreendidas enquanto movimento, práxis política e epistêmica.

Palavras-chave:pedagogias de coloniais, educação do campo, antirracismo

\section{DECOLONIALIDAD Y EDUCACIÓN DEL CAMPO: DIÁLOGOS EN CONSTRUCCIÓN}

Resumen: ¿Qué desafíos están puestos a la formación de educadoras y educadores del campo, para que género, raza y naturaleza, sean incorporados plenamente a su marco conceptual, metodológico y político, como categorías útiles para las uperación de la lógica monorracial, monocultural y heteropatriarcal que organiza la educación brasilera? Esta es la cuestión que proponemos para conducirlas reflexiones sobre los diálogos en construcción entre decolonialidad y formación de educadoras y educadores del campo. Em este ensayo, cuyo punto de partida es la actuación junto a los movimientos sociales del campo, especialmente los movimientos de mujeres, negros, quilombolas y feministas, decolonialidad y educación del campo son comprendidas como movimiento, praxis política y epistémica.

Palabras-clave: pedagogías de colônias, educación del campo, antirracismo

Submissão 24-06-2019 Aceite 04-08-2019

\section{REFLEXÕES INICIAIS}

Quem vive da floresta

Dos rios e dos mares

De todos os lugares

Onde o sol faz uma fresta

Quem a sua força empresta

Nos quilombos nas aldeias

E quem na terra semeia

Venha aqui fazer a festa Gilvan Santos ${ }^{4}$

O presente texto é um convite para que possamos juntas, juntos e juntes ${ }^{5}$ refletir

Professora do curso de Licenciatura em Educação do Campo do Departamento de Educação da Universidade Federal de Viçosa (UFV). Doutoranda do Programa de Pós-graduação em Educação da Universidade Federal de Santa Catarina (PPGE/UFSC). Membro do Grupo de Pesquisa ALTERITAS: diferença, arte e educação e do Núcleo de Educação do Campo e Agroecologia (ECOA/UFV).

$2 \quad{ }^{* *}$ Professora do Programa de Pós-Graduação em Educação (PPGE) e do Programa de Pós-Graduação Interdisciplinar em Ciências Humanas (PPGIH) da Universidade Federal de Santa Catarina (UFSC). Doutora em Educação pela UFSC. Líder do Grupo de Pesquisa ALTERITAS: diferença, arte e educação e membro do Núcleo Vida e Cuidado (NUVIC).

$3{ }^{* * *}$ Professor do Programa de Pós-Graduação em Educação (PPGE) e do Mestrado Profissional em Ensino de História (Profhistória) da Universidade Federal de Santa Catarina (UFSC). Doutor em Educação pela Universidade Estadual de Campinas. Líder do Grupo de Pesquisas Patrimônio, Memória e Educação (PAMEDUC UFSC).

4 Cada subtítulo será apresentado por um trecho da canção "Não vou sair do campo" de autoria de Gilvan Santos que, no contexto da Educação do Campo brasileira, é bastante conhecida e emblemática.

5 Utilizaremos o termo "es" provisoriamente, a fim de exercitar um giro linguístico/intersubjetivo/epistêmico/decolonial tornando a linguagem inclusiva à população LGBTI+, estimulando a 
sobre as contribuições do pensamento decolonial à formação de educadoras/es do campo. O texto emerge da atuação junto aos movimentos sociais do campo, especialmente os movimentos negros, quilombolas, movimento de mulheres e feministas. Muito do que será apresentado, nasce da semeadura em solo partilhado com aquelas/es que, submetidas/os/es a processos de subalternização, insurgiram, resistiram e se mantiveram existentes no confronto às diferentes formas de opressão, exploração e dominação.

Partimos do entendimento de que as universidades ocidentalizadas se constituem um campo fundado na matriz eurocêntrica da modernidade/colonialidade que, orientada pelo racismo/sexismo epistêmico classifica, hierarquiza, subalterniza e extermina sujeitos, corpos e conhecimentos a partir da referência colonial branca, heteropatriarcal e cristã (GROSFOGUEL, 2016, p. 25). Herdeiras dessa configuração, estão as universidades públicas brasileiras, que por vezes, (re)produzem de modo persistente e sistemático históricas desigualdades sociais elegendo como cultura acadêmica, política e curricular uma educação monolítica, enrijecida e triste. Parafraseando Paulo Freire (2011) e bellhooks (2017), uma educação bancária, destituída do entusiasmo, da curiosidade epistemológica e da boniteza do ensinar.

As pedagogias impostas por este modelo de educação são reguladas pelo euro centrismo subalternizante e epistemicida que desperdiça as experiências dos/as/es educandos/as/es, bem como das/dos/des educadoras/es em constante formação. Entretanto, como argumenta Boaventura de Sousa Santos (2010), este paradigma dominante está em crise e um novo paradigma emerge. Esta mudança de perspectiva é definida pelo autor como Epistemologias do Sul: "um conjunto de intervenções epistemológicas que denunciam a supressão, valorizam saberes que resistiram com êxito e investigam as condições de diálogo horizontal entre conhecimentos" (SANTOS; MENESES, 2010, p. 53).

Nas universidades públicas brasileiras, a implementação de políticas afirmativas especialmente por meio da reserva de vagas, faz emergir diferentes sujeitos, movimentos e práxis transformando as ausências em emergências. Neste cenário, a população do campo, negra, quilombola, indígena, LGBTI+ se apresenta, anunciando suas presenças $^{6}$ que, além de explicitar tensões no debate sobre diferença, relações 
étnico-raciais e de gênero, interrogam a cultura político-acadêmica-curricular, especialmente dos cursos de formação de professoras/es, e apontam para a urgente e necessária descolonização dos currículos. Estes grupos organizados em ações coletivas e movimentos sociais interpelam o formato colonial de produção de conhecimento e reivindicam uma formação contra-hegemônica, pluriversal, afirmativa, antirracista e feminista que emerja de suas relações e experiências no confronto às colonialidades. Esta formação chamaremos neste ensaio de decolonial.

Mas será possível descolonizar as universidades e a formação de professoras/es? Que transformações são necessárias às universidades e ao campo da formação de professoras/es para que gênero, raça e natureza sejam incorporados plenamente ao seu marco conceitual, metodológico e político, enquanto categorias de análise úteis à superação da lógica capitalista, monorracial, monocultural e heteropatriarcal que organiza a educação brasileira?

Diferentes intelectuais indicam caminhos possíveis a partir destas indagações, mas ainda nos falta ampliar estas reflexões às particularidades dos currículos e da formação de educadoras/es do campo, que neste texto é compreendida como potência, por apresentar algumas respostas ao desafio decolonial.

A luta por uma educação que reconheça o vínculo terra-território, força m(a)otriz da vida no campo, completa no Brasil 50 anos, tornando o movimento da educação do campo um potente interlocutor com o qual podemos dialogar sobre pedagogias decoloniais. Para tanto, apresentamos brevemente alguns conceitos e categorias compartilhadas pelo pensamento decolonial que, em diálogo com a experiência de uma Licenciatura em Educação do Campo do interior de Minas Gerais, poderão indicar contribuições para uma formação de educadoras/es do campo pluri epistêmica, antirracista e feminista.

\section{DECOLONIALIDADE: NOTAS INTRODUTÓRIAS ÀS PEDAGOGIAS DECOLONIAIS}


Construir uma nação

Construir soberania

Pra viver o novo dia

Com mais humanização.

Gilvan dos Santos

Decolonialidade é compreendida neste ensaio como uma "prática de oposição e intervenção, que surgiu no momento em que o primeiro sujeito colonial do sistema mundo moderno/colonial reagiu contra os desígnios imperiais que se iniciou em 1492" (BERNADINO-COSTA; GROSFOGUEL, 2016, p. 17). No argumento de Walter Mignolo (2010), é também desobediência política e epistêmica à retórica da modernidade e à lógica da colonialidade, entendidas como eixos constitutivos do padrão mundial do poder capitalista. Este por sua vez, sustentado pela imposição da classificação da população mundial de acordo com a ideia de raça definida como "uma construção mental que expressa a experiência básica da dominação colonial e que desde então permeia as dimensões mais importantes do poder mundial, incluindo sua racionalidade" (QUIJANO, 2005, p. 107). Esta classificação institucionalizou a inferioridade e justificou a violência etnocida, genocida e epistemicida contra "identidades societais historicamente novas: negros, azeitonados, amarelos, brancos, mestiços, e as identidades geoculturais do colonialismo: América, África, Extremo Oriente, Ocidente, Ásia” (QUIJANO, 2010, p.85).

A decolonialide ainda pode ser compreendida como um projeto acadêmicopolítico latino-americano que emerge da crítica ao pós-colonialismo e ganha materialidade com o programa de investigação modernidade/colonialidade ${ }^{7}$. A opção descolonial $^{8}$, ou o giro decolonial defendido pelo grupo, propõe uma descolonização epistêmica, política e teórica a partir do Sul como caminho para a transformação planetária. original que resgata e insere a América Latina como o continente fundacional do colonialismo, e, portanto, da modernidade;

(b) a importância da América Latina como primeiro laboratório de teste para o racismo a serviço do colonialismo; (c) o reconhecimento da diferença colonial, uma diferença mais difícil de identificação empírica na atualidade, mas que fundamenta algumas origens de outras diferenças; (d) a verificação da estrutura opressora do tripé colonialidade do poder, saber e ser como forma de denunciar e atualizar a continuidade da colonização e do imperialismo, mesmo findados os marcos históricos de ambos os processos; (e) a perspectiva decolonial, que fornece novos horizontes utópicos e radicais para o pensamento da libertação humana, em diálogo com a produção de conhecimento". (BALLESTRIN, 2013, p.110).

8

Antes de avançarmos ainda há algo a negritar: o que distingui o decolonial do descolonial? De acordo com Luciana Ballestrin (2013, p.108), trata-se da sugestão feita por Catherine Walsh para a utilização da expressão "decolonização" - com ou sem hífen - e não "descolonização" como sugerem outros intelectuais. A supressão da letra "s" marcaria a distinção entre o projeto decolonial do Grupo Modernidade/Colonialidade e a ideia histórica de descolonização, via libertação nacional durante a Guerra Fria. Neste ensaio utilizaremos decolonial. 
A matriz colonial de poder apresentada por intelectuais do grupo modernidade/colonialidade articula mutuamente os domínios: 1) do trabalho e seus produtos; 2) do sexo, seus produtos e a reprodução da espécie; 3) da subjetividade e seus produtos materiais e intersubjetivos, incluindo o conhecimento a memória; 4) do controle, da autoridade e seus instrumentos, de coerção em particular; 5) o controle da natureza e seus recursos. Assim, é possível pensar em quatro dimensões da colonialidade imbricadas entre si: colonialidade do poder, que é a maneira como opera o padrão de poder mundial capitalista; a colonialidade do saber, que pressupõe o eurocentrismo como perspectiva hegemônica; do ser, que desumaniza e inferioriza a partir do referencial branco, heteropatriarcal, cristão, europeu; e a colonialidade cosmogônica ou da natureza, que para Catherine Walsh (2009, p. 15) "pretende anular as cosmovisões, filosofias, religiosidades, princípios e sistemas de vida".

Portanto, são processos decoloniais aqueles que buscam "desvincularse, desligarse, desgancharse de la tirania de la matriz colonial del poder" (MIGNOLO, 2010, p. 23) e reconhecem que “outros mundos são possíveis”. Outra característica distintiva do projeto decolonial é a produção de conhecimento e de narrativas a partir de loci geopolíticos e corpo-políticos de enunciação (BERNADINO-COSTA; GROSFOGUEL, 2016, p. 15). É também o entendimento de que é necessário “aprender a desaprender, e aprender a cada passo". (MIGNOLO, 2008, p. 305)

Importa-nos negritar, conforme também pontuam Bernadino-Costa e Grosfoguel (2016, p. 17) que "sem utilizar o termo colonialidade já era possível encontrarmos a ideia que gira entorno desse conceito em toda a tradição do pensamento negro", como por exemplo em W.E.B. Du Bois, Oliver Cox, Franntz Fanon, Cedrice Robison, Aimé Cesaire, Eric Willims, com as feministas negras Angela Davis, bellhooks, Patricia Hill Collings entre outras, além de intelectuais brasileiras como Lélia Gonzales, Beatriz Nascimento, Sueli Carneiro, bem como Clóvis Moura, Abdias do Nascimento, Guerreiro Ramos, que pensam a população negra na sociedade brasileira a partir do seu lugar social, político e epistêmico.

Outro destaque é que se por um lado há um avanço nos programas acadêmicos em dialogar com o pensamento decolonial, paradoxalmente, elegemos para os currículos intelectuais homens e do circuito universitário, bem como podemos observar nas páginas deste próprio ensaio, o que se configura como mais um desafio decolonial: como superar o sexismo e racismo também impregnado em nós, intelectuais 
decoloniais? Por que privilegiamos autores brancos em um contexto de ampla produção negra e indígena? É preciso questionar porque mesmo no âmbito do pensamento decolonial as mulheres, especialmente negras e indígenas são conhecidas tardiamente e têm menos prestígio acadêmico, sendo seus percursos intelectuais sombreados pelos percursos masculinos 9 .

A opção decolonial que nos convida Walter Mignolo (2008; 2010) pressupõe a incorporação das categorias de gênero, raça e natureza no seu marco conceitual e político. Além da realização da pluriversalidade epistêmica como projeto universal, da desobediência epistêmica e da construção de uma gramática da descolonialidade a partir do pensamento de fronteira que, para Gloria Anzaldua, é compreendido como um lugar de ponto de encontro no qual se amplia a visão de mundo, onde "as possibilidades são inúmeras, uma vez que tenhamos decidido agir, em vez de apenas reagir" (ANZALDUA, 2005, p. 706).

Ainda no empenho de definir que é decolonialidade, gostaríamos de destacar e reconhecer as lutas dos movimentos sociais que a partir de uma perspectiva ampla, intercultural e pluri epistêmica, confrontam as diferentes dimensões da colonialidade.

No contexto deste ensaio, lançamos nosso olhar aos movimentos socias do campo, em especial aqueles que compõem o movimento da educação do campo. Muito embora enquanto movimento ele se constitua a partir da segunda década dos anos 2000, podemos entender a luta pelo direito à educação do campo desde a criação das primeiras escolas do campo surgidas no Brasil em 1969, que reverbera mais tarde na luta pela formação de educadoras/es do campo por meio de pedagogias que reconhecem e valorizam os sujeitos e as epistemologias do campo. Entendemos que aqui há um potente diálogo em construção.

\section{REAPRENDER PEDAGOGIAS “ESQUECIDAS”}

O povo camponês

O homem e a mulher

O negro quilombola Com seu canto de afoxé Ticuna, Caeté Castanheiros, seringueiros Pescadores e posseiros Nesta luta estão de pé. Gilvan dos Santos

9

Para conhecer algumas intelectuais decoloniais consultar: AZKUE, IrantzuMendia; LUXÁN, Marta; LEGARRETA, Matxalen; GUZMÁN, Gloria; ZIRION, Iker; CARBALLO, JokinAzpiazu. (eds.). Otras formas de (re)conocer: Reflexiones, herramientas y aplicaciones desde lainvestigación feminista. 2014. MILLÁN, Márgara. (Coord.) Más alládel feminismo: caminhos para andar. México. Red de Feminismos Descoloniales, 2014. 
A Educação do Campo nasce das lutas por uma educação básica referenciada nas especificidades e demandas dos movimentos sociais do campo, protagonizada inicialmente pelo Movimento dos Trabalhadores Sem Terra, avançando para lutas mais amplas pela educação do conjunto de trabalhadores/as do campo, compreendendo o direito à educação desde a educação infantil até universidade (CALDART, 2012). Este projeto de educação busca reverter duas características fundamentais do sistema educacional: a lógica centrada no urbano e a predominância de políticas públicas generalistas que desconhecem as especificidades da população do campo, "produzido historicamente como lugar da carência e do atraso, um espaço social a ser desenvolvido dentro dos padrões urbanos, e não em função de suas características próprias" (ARRUTI, 2011, p.116).

É no âmbito destas lutas por um projeto de campo livre do agronegócio e por uma educação diferenciada, que diferentes sujeitos e movimentos do campo em articulação com as universidades constituíram o movimento da educação do campo no Brasil. Nesse sentido, em 2012 sob tenso debate, são criadas mais de quarenta Licenciaturas em Educação do Campo no país ${ }^{10}$, uma delas na Universidade Federal de Viçosa: a Licenciatura em Educação do Campo com Habilitação em Ciências da Natureza e enfoque na Agroecologia (LICENA).

A partir de parcerias construídas historicamente com os movimentos sociais da região orientados para uma agricultura de base agroecológica e o fortalecimento da agricultura familiar camponesa, da agroecologia e da educação popular e do campo, o curso inaugura na universidade a reserva de vagas para trabalhadoras/es do campo, educadoras/es e egressas/os/es de escolas do campo, indígenas e quilombolas.

Institucionaliza uma pedagogia com foco em práticas e processos educativos populares e emancipatórios que nascem das/nas lutas e estimulam a formação de comunidades educativas; que reconhece e valoriza os conhecimentos dos povos do campo articulando-os à conhecimentos científicos formando uma ecologia de saberes Superior e aos Institutos Federais de Educação, Ciência e Tecnologia, a apresentarem Projetos Pedagógicos de cursos presenciais de Licenciatura em Educação do Campo do Programa de Apoio à Formação Superior em Licenciatura em Educação do Campo - PROCAMPO, em cumprimento à Resolução CNE/CEB n ${ }^{\circ}$, de 3/4/2002 (Institui Diretrizes Operacionais para a Educação Básica nas Escolas do Campo), ao Decreto n ${ }^{\circ} 7.352$, de 04/11/2010 (Dispõe sobre a política de educação do campo e o Programa Nacional de Educação na Reforma Agrária - PRONERA) e em consonância com o Programa Nacional de Educação do Campo - PRONACAMPO. 
como propõe Santos e Meneses (2010), além de inserir em sua proposta curricular, política e pedagógica a natureza, especialmente por meio da agroecologia e dos saberes tradicionais de manejo e produção de vida no campo.

A implantação da Licenciatura e a subsequente presença de estudantes trabalhadores/as rurais, indígenas e sobretudo mulheres negras quilombolas, apresentam um horizonte de superação ao desafio de descolonizar a formação de educadoras/es do campo, historicamente ancorada em uma análise da sociedade a partir da categoria trabalho. Neste ponto, localizo uma importante contribuição do pensamento decolonial. Vejamos.

Para Catherine Walsh a matriz quadrimensional da colonialidade evidencia que a diferença construída e imposta desde a colônia não é uma diferença unicamente assentada sobre a cultura, ou um reflexo da dominação enraizada em questões de classe como eixo central. Para a autora, "a matriz da colonialidade afirma o lugar central da raça, do racismo e da racialização como elementos constitutivos e fundantes das relações de dominação" impostas pelo poder colonial eurocêntrico (WALSH, 2009, p. 15-16).

Tal argumento, nos convida a pensar o contexto da formação de educadoras/es do campo no Brasil. Quem são estes diversos sujeitos e movimentos do campo, que epistemologias e pedagogias trazem à universidade, que narram e ensinam suas lutas e seus corpos? Usando o argumento de Santos (2010), torna-se necessário desvelar estas ausências para iluminar as emergências.

Para Miguel Arroyo, "o reconhecimento da diversidade não enfraquece, e sim fortalece os princípios em que se assenta a construção teórica da educação do campo, do projeto de campo e de sociedade" (ARROYO, 2012, p.232). Portanto, pensar a diversidade na formação de educadoras/es do campo é identificar as diferenças étnicoraciais, de gênero, de sexualidade, classe, geração, entre outras, que compõem os sujeitos e movimentos do campo. É (re)conhecer os diferentes processos de resistências ao capitalismo heteropatriarcal/branco/eurocentrado. É também (re)conhecer o que permanece inexistente, criando condições para a valorização e validação de identidades, culturas, corpos, epistemologias e práticas historicamente subalternizadas, entre elas pedagogias "esquecidas", ou melhor dizendo invisibilizadas.

Para Santos e Meneses (2010, p.11) o colonialismo além de todas as dominações por que é conhecido, foi também uma dominação epistemológica, "uma relação extremamente desigual entre saberes que conduziu a supressão de muitas formas de saber próprias dos povos e nações colonizados, relegando-os à subalternidade", à invisibilidade produzindo-os como inexistente. E para o autor e a autora, inexistência 
significa não existir sob qualquer forma de ser relevante ou compreensível.

Nesse sentido, a perceptiva crítica da interculturalidade, conceito compartilhado pelas/os/es principais intelectuais decoloniais, cria condições à pedagogia e práxis decolonial. Para Walsh, a interculturalidade é: “o trabalho que procura desafiar e derrubar as estruturas sociais políticas e epistêmicas da colonialidade. Um pensar e agir pedagógico fundamentados na humanização e descolonização; isto é, no re-existir e no re-viver como processos de re-criação" (WALSH, 2009, p.38). Enquanto projeto político, social, epistêmico e ético a interculturalidade crítica se preocupa:

[...] com a exclusão, negação e subalternização ontológica e epistêmico-cognitiva dos grupos e sujeitos racializados; com as práticas - de desumanização e de subordinação de conhecimentos que privilegiam alguns sobre outros, "naturalizando" a diferença e ocultando as desigualdades que se estruturam e se mantêm em seu interior. Mas, e adicionalmente, se preocupa com os seres de resistência, insurgência e oposição, os que persistem, apesar da desumanização e subordinação. Por isso, seu projeto se constrói de mãos dadas com a decolonialidade, como ferramenta que ajude a visibilizar estes dispositivos de poder e como estratégia que tenta construir relações - de saber, ser, poder e da própria vida radicalmente distintas. (WALSH, 2009, p.23).

Dessa maneira, as pedagogias decoloniais podem ser entendidas como processo e prática sociopolíticos transformadores assentados nas realidades de dentro e fora das escolas, que nasce das subjetividades, histórias e lutas das pessoas, vividas num mundo regido pela estrutura colonial/capitalista e, portanto, racializada e geneirificada.

Ainda para Walsh, a interculturalidade enquanto ferramenta pedagógica decolonial:

questiona continuamente a racialização, subalternização, inferiorização e seus padrões de poder, visibiliza maneiras diferentes de ser, viver e saber e busca o desenvolvimento e criação de compreensões e condições que não só articulam e fazem dialogar as diferenças num marco de legitimidade, dignidade, igualdade, equidade e respeito, mas que - ao mesmo tempo - alentam a criação de modos "outros"- de pensar, ser, estar, aprender, ensinar, sonhar e viver que cruzam fronteiras. A interculturalidade crítica e a de-colonialidade, nesse sentido, são projetos, processos e lutas que se entrecruzam conceitualmente e pedagogicamente, alentando forças, iniciativas e perspectivas éticas que fazem questionar, transformar, sacudir, rearticular e construir. (WALSH, 2009, p. 25)

No contexto da educação do campo, merece atenção especial as pedagogias diaspóricas e de resistência materializadas no corpo da população negra do campo. São experiências artísticas e culturais que emergem na fronteira e conturbam, tencionam e 
deslocam o pensamento abissal e o epistemicídio ${ }^{11}$ dele decorrente uma vez que afirmam, validam e rompem com o silenciamento sobre suas interdições do espaço de produção do conhecimento durante séculos. Neste processo, o corpo negro constitui-se como espaço de luta, de reconstrução de narrativas, de memórias insurgentes, de resistência cotidiana e coletiva, um espaço de experiência de (re)criação e existências resistentes.

Para Nilma Lino Gomes (2017) o movimento negro é educador e detentor de saberes construídos na luta por emancipação em um país com a mais longa história de escravidão das Américas. Nesse sentido, o pensamento e a prática decolonial reposiciona os corpos negros insurgentes e resistentes, produtores de saberes e pedagogias. Portanto, conhecer, validar e estabelecer um diálogo com as diferentes práticas e processos formativos dos sujeitos do campo, com especial atenção às práticas artístico-culturais e de luta materializadas no e pelo corpo, pode qualificar o processo de formação de educadoras/es e a almejada descolonização dos currículos “enriquecendo a produção de saberes e forçando uma revisão do eurocentrismo subalternizante e absoluto que marca a vida universitária brasileira." (CARVALHO, 2001, p. 63).

A efetiva institucionalização de práticas decoloniais (interculturais, antirracistas, feministas, ecológicas, contra-hegemônicas) requer pensar sob um paradigma que não separe corporeidade, trabalho, cognição, emoção, política e arte, e sim um paradigma que “compreende que não há hierarquias entre conhecimentos, saberes e culturas, mas, sim, uma história de dominação, exploração, e colonização que deu origem a um processo de hierarquização de conhecimentos, culturas e povos." (GOMES, 2012, p. 102)

A proposta pedagógica da LICENA encontra ressonância com este "novo paradigma" ou como propõe Miguel Arroyo (2014) com o desafio de reconhecer “outros sujeitos", re(criando) "outras pedagogias", que recoloque no contexto de formação de educadoras/es pedagogias "esquecidas", invisibilizadas, tornadas inexistentes, como aquelas que nascem no confronto às colonialidades. Para a LICENA, o corpo, a memória, as artes, a partilha, a mística, o trabalho, as lutas são elementos constitutivos e centrais articulados em quatro pilares inter-relacionados: Agroecologia, Trabalho como Princípio Educativo, Alternâncias Educativas e Educação Popular. Esta racialidade/biopoder que além da anulação e desqualificação do conhecimento dos povos subjugados, cria um processo persistente de produção da indigência cultural pela negação ao acesso à educação, pela produção da inferiorização intelectual e pelos diferentes mecanismos de deslegitimação do negro como portador e produtor de conhecimento. (CARNEIRO, 2005, p. 97). 
organização curricular integra aspectos teóricos e práticos por meio dos princípios da Pedagogia da Alternância na qual as possibilidades pedagógicas são enriquecidas pela relação de alternância entre diferentes tempos e espaços pedagógicos: os acadêmicos e os da vida comunitária, nomeados (Tempo-Escola/Universidade e Tempo-Comunidade).

A Alternância Pedagógica se constitui nas interações entre estudantes, universidade, educadoras/es e a materialidade dos territórios educativos, buscado oportunizar tempos e espaços para a vivência e a convivência na universidade, nos territórios, nas organizações e movimentos sociais. Nesse processo, a finalidade é articular à realidade dos territórios aos componentes curriculares propiciando o (re)conhecimento das/os/es educandas/os/es enquanto sujeitos/as/es individuais e coletivos do território educativo em que vivem; experimentar e ampliar o repertório de conhecimento acerca dos modos de produção de vida, cultura e trabalho e; elaborar o diagnóstico das experiências educativas hegemônicas e contra-hegemônicas engendradas nos territórios educativos.

Ademais, possibilita que nós, educadoras/es em constante formação, (re)conheçamos as diferentes e diversas experiências, estratégias de luta, epistemologias e pedagogias que compõem estes territórios. Sob essa dinâmica, a Alternância Pedagógica da LICENA pressupõe um diálogo de saberes, ou nas palavras de Santos (2010), uma ecologia de saberes, organizada em momentos de escuta, questionamentos e intervenções nos quais a dialogicidade, o entusiasmo e o afeto expressam a essência de uma "educação como prática da liberdade" (hollks, 2017)

A proposta pedagógica da LICENA além de não estabelecer fronteiras rígidas entre as áreas das Ciências da Natureza, Ciências Humanas e Ciências Sociais, coloca o saber popular em diálogo como o saber científico utilizando ferramentas pedagógicas já consolidadas pelas experiências dos movimentos sociais do campo e também por ferramentas específicas elaboradas a partir da (co)laboração docente: Plano de Estudo; Colocação em Comum; Excursões pedagógicas; Acompanhamento do Tempo Comunidade; Culturais; Oficinas; Espaço Aberto; Avaliação; LiCine; Embarque/Chegança ${ }^{12}$. 
Esse conjunto de ferramentas pedagógicas permite que as/os/es diferentes sujeitos do campo enunciem não apenas os valores, práticas e saberes dos seus territórios educativos, mas também os processos de produção e reprodução do conhecimento, os modos de ser, se relacionar e ler o mundo. Permite a (re)criação de pedagogias pensadas a partir das/dos/es próprias/os/es sujeitas/os/es do campo.

A formação de educadoras/es do campo é potente por: interpelar a produção de conhecimento que tem origem e ponto de chegada nos sujeitos e modos de produção/reprodução de vida da cidade; denunciar a cumplicidade entre as pedagogias hegemônicas e o padrão mundial/colonial/capitalista de poder; romper com os regimes de autorização discursiva a medida em que nasce de sujeitos que falam a partir de seus lugares epistêmicos, sociais e políticos; anunciar formas outras de aprender e ensinar que reconhecem e validam os afetos, os corpos, a arte, a alegria, a festa, a comunhão, as diferenças, a natureza e as lutas enraizadas em uma epistemologia de (re)existência, ou como preferimos nomear: de existências resistentes; (re)cria pedagogias ancestrais, na força que emana do círculo pedagógico, do fazer com, do partilhar, do (con)viver, da mística, da roda de conversa, da escuta profunda, da presença autêntica e do cuidado.

Portanto, pensar as contribuições da decolonialidade para a formação de educadoras/es do campo nos remete a experiência de olhar, escutar e estar com as/os/esmúltiplos sujeitas/os/es do campo. Desde o seu nascedouro a educação do campo se enraíza nesta experiência de pensar com e a partir do camponês. Mas quem é este camponês?

O Brasil é o país com a mais longa história de escravidão das Américas, com uma tradição patriarcal que atravessa diferentes dimensões sociais. Tal situação ganha complexidade ao se pensar a população negra do campo que é subalternizada e marginalizada do sistema educacional e das políticas públicas. O campo permanece sem corpo, o camponês como categoria universal, embora "ainda que no concreto real os sujeitos trabalhadores do campo sejam diversos e nem todos caibam no conceito estrito de trabalhadores camponeses." (CALDART, 2012, p.15).

Portanto, a incorporação das categorias raça, gênero e natureza a partir de uma

Extensão para a Agricultura Familiar: no âmbito da política nacional de assistência técnica e extensão rural. $1^{a}$ ed. Brasília: Ministério do Desenvolvimento Agrário, 2015. p. 355-363. Rede Dragon Dreaming Brasil. Guia Prático Dragon Dreaming: Uma Introdução Sobre como Tornar seus Sonhos em Realidade Através de Projetos Colaborativos. Versão 4.0, Junho de 2015. CARVALHO, Cristiene Adriana da Silva e MARTINS, Aracy Alves (orgs). Práticas artísticas do campo. Belo Horizonte: Autentica Editora, 2016. (Coleção Caminhos da Educação do Campo) 
abordagem decolonial são fundamentais para explicar e superar as profundas desigualdades educacionais que atravessam o campo brasileiro. Talvez a maior contribuição da decolonialdedade é o convite à re-criação de pedagogias que localizem lado a lado as dimensões de raça, gênero, natureza e trabalho.

FINALIZANDO

Não vou sair do campo

Pra poder ir pra escola

Educação do campo

É direito e não esmola.

Gilvan Santos

A inversão da lógica colonial pressupõe escutar e olhar com atenção os aportes provenientes dos lugares subalternizados, reconhecendo experiências comuns de grupos que se consideram cultural e politicamente distintos (BILLINGS, 2006, p. 264), além de provocar à descolonização das paisagens mentais, que implica uma revisão radical dos seus cânones, tanto teóricos como temáticos (CARVALHO, 2001, p.111).

Portanto, a superação dos desafios postos à formação de educadoras/es do campo está enraizada na compreensão da matriz eurocêntrica da modernidade/colonialidade que, orientada pelo racismo/sexismo epistêmico classifica, hierarquiza, subalterniza e extermina sujeitos, corpos e conhecimentos a partir da referência colonial branca, heteropatriarcal e cristã, como apresentado por Grosfoguel (2016, p. 25) e discutido por nós anteriormente. Esta compreensão é potente pois: aprofunda a discussão sobre as desigualdades étnico-raciais e de gênero no campo brasileiro indicando caminhos para sua superação; qualifica o engajamento e militância de educadoras/es e educandas/os/es nos processos de resistência ao capitalismo patriarcal e ao racismo; convoca os cursos de Licenciatura em Educação do Campo ao constante aprendizado que nasce nas e das diferentes lutas dos diferentes movimentos que os constituem; interpela à reconfiguração de seus currículos a partir da produção de conhecimento negra e indígena, ainda invisibilizada pelo conjunto teórico da educação do campo; amplia a percepção de que a luta antirracista e feminista é uma questão que diz respeito ao conjunto da sociedade brasileira, não se restringindo às bandeiras de luta dos movimentos negros, quilombolas, indígenas, de mulheres e feministas.

Vale sublinhar, como nos ensina Nilma Lino Gomes, que descolonizar os currículos e a formação de professoras/es é uma "mudança estrutural, conceitual, epistemológica e política" (GOMES, 2012, p. 105). 
O cenário sociopolítico que se compõe de intensificação das lutas pela democratização da educação pública e garantia de direitos é terreno fértil ao diálogo entre formação de educadoras/es e decolonialidade. As reflexões apresentadas neste texto podem contribuir com este diálogo em construção, ampliando as perspectivas para a formação de educadoras/es do campo e afirmando a diversidade de sujeitos, movimentos, culturas, ação política e epistemologias que (re)produzem a vida no campo brasileiro.

Vamos juntas, juntos e juntes, somando energias para caminhar e transformar.

\section{REFERÊNCIAS}

ANZALDUA, Gloria. La consciência de lamestiza. Rumo a uma nova consciência. Revista de estudos Feministas, Florianópolis, v. 13, n. 3, p. 704-719, Dez, 2005.

ARROYO. Miguel. Diversidade. In: Dicionário da Educação do Campo(Org) CALDART, Roseli Salete; PEREIRA, Isabel Brasil; ALENTEJANO, Paulo Alentejano; FRIGOTTO, Gaudêncio. Rio de Janeiro, São Paulo: Escola Politécnica de Saúde Joaquim Venâncio, Expressão Popular, 2012, p. 229-237.

ARROYO. Miguel. Outros Sujeitos, Outras Pedagogias. Petrópolis, RJ: Vozes, 2014. ARRUTI, José Maurício. Da ‘educação do campo' à 'educação quilombola': Identidade, conceitos, números, comparações e problemas. Raízes,v.31, n.1, jan-jun /2011.

BERNARDINO-COSTA, Joaze; GROSFOGUEL, Ramon. Decolonialidade e perspectiva negra. Revista Sociedade e Estado - v. 31, n. 1, jan-abril/2016.

BILLINGS, Glória. In: DENZIN. N; LINCOLN, Y. (org). O planejamento da pesquisa qualitativa: teorias e abordagens. Discursos racializados e epistemologias étnicas. Porto Alegre: Artmed, 2006, p. 259-279.

CALDART, Roseli Salete. Educação do campo. In: Dicionário da Educação do Campo. (Org) CALDART, Roseli Salete; PEREIRA, Isabel Brasil; ALENTEJANO, Paulo Alentejano; FRIGOTTO, Gaudêncio. Rio de Janeiro, São Paulo: Escola Politécnica de Saúde Joaquim Venâncio, Expressão Popular, 2012, 259-267.

CARNEIRO, Sueli. A construção do outro como não ser como fundamento do ser. 2005. Tese Doutorado em Educação. Programa de Pós-Graduação em Educação da Universidade de São Paulo. São Paulo. 2005.

CARVALHO, José Jorge de. O olhar etnográfico e a voz subalterna. Horizontes antropológicos, v. 7, n. 15, p. 107-147, 2001.

FREIRE, Paulo. Pedagogia da Autonomia. São Paulo: Paz e Terra, 2011.

GOMES, Nilma Lino. Relações étnico-raciais: educação e descolonização dos currículos. Revista Currículo sem fronteiras, Porto Alegre, v. 12, n. 1, 2012, p. 98-109.

GOMES, Nilma Lino. O movimento Negro Educador: Saberes construídos nas lutas por emancipação. Petrópolis: Vozes, 2017.

GROSFOGUEL, Ramón. A estrutura do conhecimento nas universidades ocidentalizadas: racismo/sexismo epistêmico e os quatro genocídios/epistemicídiosdo longo século XVI. Revista Sociedade e Estado - v. 31, n. 1, jan-abril/2016. p. 25-49. 
hooks, bell. Ensinando a transgredir: a educação como prática de liberdade. Tradução Marcelo Brandão Cipolla. 2ed. São Paulo: Editora WMF Martins Fontes, 2017. QUIJANO, Anibal. Colonialidade do poder e classificação social. In: SANTOS, Boaventura Sousa Santos; MENESES, Maria Paula (Orgs.). Epistemologias do Sul. São Paulo: Editora Cortez, 2010, p. 84-130.

QUIJANO, Anibal. Colonialidade do poder, eurocentrismo e América Latina. LANDER, E. (Org.). A colonialidade do saber:eurocentrismo e ciências sociais. Perspectivas latino-americanas. Buenos Aires: CLACSO, 2005.

MIGNOLO, Walter. Desobediência epistêmica: a opção descolonial e o significado de identidade em política. Traduzido por: Ângela Lopes Norte.Cadernos de Letras da UFF - Dossiê: Literatura, língua e identidade, n 34, p. 287-324, 2008.

MIGNOLO, Walter. Desobediencia epistémica: retórica de la modernidade, lógica de la colonialidade, gramática de la descolonialidad. $1^{\text {a }}$ ed. Buenos Aires: Del Signo, 2010.

WALSH, Catherine. Interculturalidade Crítica e Pedagogia Decolonial: in-surgir, re-existir e re-viver. In: CANDAU, Vera Lúcia (org) Educação Intercultural na América Latina: entre concepções, tensões e propostas. 2009, p. 12-42 